\title{
CHECAGEM DE FATOS NUMA DEMOCRACIA EM XEQUE: implementação da Plataforma Sem Migué nas eleições municipais de São Luís
}

FACT-CHECKING IN A CRUMBLING DEMOCRACY : Implementation of "Sem Migué" platform during local elections in São Luís

VERIFICACIÓN DE HECHOS EN UMA DEMOCRACIA EN JAQUE: Implementación de la plataforma "Sem Migué" en las elecciones municipales de São Luís

\section{Jorge Araújo Martins Filho}

Mestrando em Comunicação. Aluno do Programa de Pós-graduação em Comunicação - Mestrado Profissional (PPGCOMPRO) da Universidade Federal do Maranhão. jfilho.araujo@gmail.com

\section{$\underline{0000-0001-5463-6950}$}

\section{Li-Chang Shuen}

Doutora em Ciências Sociais (UnB). Professora do Programa de Pós-graduação em Comunicação Mestrado Profissional (PPGCOMPRO) da Universidade Federal do Maranhão). li.chang@ufma.br

\section{0-0001-9192-6471}

Correspondência: Universidade Federal do Maranhão, Av. dos Portugueses, 1966 - Bacanga, CEP 65080-805, São Luís, Brasil.

Recebido em: 16.02.2021.

Aceito em: 16.04.2021.

Publicado em: 01.07.2021.

\begin{abstract}
RESUMO:
O objetivo desta pesquisa é testar a aplicabilidade de um modelo de factchecking colaborativo e descentralizado no âmbito das eleições municipais de São Luís/MA em 2020. Esse modelo foi materializado em uma plataforma intitulada "Sem Migué", na qual checadores voluntários tiveram a oportunidade de publicar suas próprias reportagens em fóruns de verificação. $O$ experimento busca investigar de que forma essa prática é capaz de ajudar os participantes a lidar com o fenômeno da desinformação. Os resultados vão subsidiar a elaboração de uma versão atualizada do modelo.
\end{abstract}

PALAVRAS-CHAVES: Desinformação; Democracia; Jornalismo; Fact-checking.

\section{Introdução}

Este artigo apresenta um relato do experimento realizado no âmbito das eleições municipais de São Luís em 2020 com o objetivo de testar a aplicabilidade de um modelo colaborativo e descentralizado de fact-checking a partir de uma plataforma intitulada "Sem Migué". Para viabilizar esse teste, recrutamos 24 voluntários - entre jornalistas e não-jornalistas - que receberam treinamento sobre a metodologia adotada e tiveram acesso aos fóruns de verificação onde todos poderiam publicar suas apurações sobre o grau de veracidade das falas de candidatos a prefeito. A pesquisa buscou investigar de que forma a experiência com esse modelo de checagem poderia ajudar os participantes a lidar com o fenômeno da desinformação. Desenvolvemos um mínimo produto viável, que foi experimentado ao longo do período de propaganda eleitoral até a data do segundo turno das eleições. 
Consideramos o conceito de desinformação adotado por Claire Wardle e Hossein Derakhshan (2017), que o definem como a disseminação de informações falsas com a intenção de causar dano. O fenômeno é comumente inserido no contexto da abundância de dados processados e transmitidos por meio das tecnologias digitais e seus fluxos descentralizados de informação e comunicação. Esse cenário é subjacente à crise de legitimidade das instituições de referência - uma delas o jornalismo - em diversas democracias liberais à medida em que crescem discursos e movimentos que têm sido chamados por alguns autores de populismo autoritário ou de extrema direita (BENKLER; FARRIS; ROBERTS, 2018; NORRIS; INGLEHART, 2019). Esses elementos fazem parte do atual ecossistema de mídia, em que a produção e difusão de notícias não são mais exclusivamente controladas pelos veículos de jornalismo profissional.

Nesse sentido, os conteúdos enganosos espalhados pela internet também têm sido chamados de fake news, termo que evitamos utilizar devido à confusão conceitual que pode ocasionar - afinal, se uma informação é falsa, não deveria ser considerada notícia. Além disso, a desordem da informação é algo bem mais abrangente do que a esfera da produção noticiosa implicada no uso da palavra news (HAIDEN; ALTHUIS, 2018). Outro problema está no caráter de novidade. Apesar do discurso em defesa da verdade e dos ideais de profissionalismo, compreendemos a imprensa tradicional como um agente político capaz de enganar desde muito antes do advento das redes digitais. Não há nada de novo nisso. O ineditismo do fenômeno da desinformação está na facilidade estendida a um leque maior de grupos e atores sociais de obter ganhos políticos e/ou econômicos por meio da proliferação de narrativas mentirosas ou distorcidas.

Por mais que recentemente tenham se multiplicado as agências de checagem de fatos e debunking de boatos (MANTZARLIS, 2018), essas iniciativas vinculadas ao campo do jornalismo profissional não conseguem verificar a totalidade do conteúdo duvidoso que circula pela internet ou mesmo garantir que as correções tenham o mesmo alcance das peças de desinformação. Muitas vezes, as informações falsas continuam sendo compartilhadas mesmo depois de desmentidas pelas agências (REIS; MELO; GARIMELLA; BENEVENUTO, 2020).

Isso pode ocorrer porque, por diversas razões, há pessoas que não se importam se a informação compartilhada é falsa ou não, contanto que fortaleça suas agendas políticas (MENDONÇA; FREITAS, 2019). Mas também há pessoas que acabam sendo enganadas por aqueles que deliberadamente espalham conteúdo fabricado ou distorcido. Nesses casos, a prática da checagem de fatos pode ser útil, mas as agências 
costumam operar em um modelo de negócios baseado na escassez de recursos, enquanto a desinformação explora a lógica da abundância e descentralização nas redes. Assim, propomos um modelo colaborativo e descentralizado de fact-checking - de modo a disseminar a prática da checagem como algo que qualquer cidadão é capaz de realizar, desde que tenha acesso aos recursos tecnológicos e conhecimento das ferramentas disponíveis para esse fim.

Trata-se de uma pesquisa-ação, uma vez que o objetivo é não apenas descrever a realidade, mas também realizar uma intervenção (GIL, 2008). Os indicadores utilizados para avaliar os resultados da experiência são o desempenho das postagens realizadas na plataforma Sem Migué, os questionários aplicados com os voluntários e a observação participante conduzida ao longo do trabalho. Devido à pandemia de Covid-19, todos os encontros com os participantes do estudo foram realizados no ambiente on-line. Os canais de comunicação utilizados foram o Google Meet, Whatsapp e e-mails.

As próximas seções estão organizadas conforme as etapas do plano de ação referente ao experimento. A primeira parte apresenta como chegamos à materialização do nosso mínimo produto viável, a plataforma Sem Migué. A segunda descreve como se deu na prática o teste desse modelo de checagem de fatos colaborativo e descentralizado, evidenciando suas potencialidades e limitações. Por fim, nas considerações finais sintetizamos os principais resultados e explicamos resumidamente como eles nos ajudarão a atualizar o modelo que poderá ser replicado em experiências futuras.

\section{Viabilização de um mínimo produto viável}

No jargão do empreendedorismo tecnológico, o mvp ou "mínimo produto viável" é a versão preliminar de um produto - completa o suficiente apenas para medir o impacto e o valor entregue aos usuários (MOOGK, 2012). Nesta pesquisa, buscamos viabilizar um mvp que permitisse cumprir o propósito de testar a aplicabilidade de um modelo colaborativo e descentralizado de fact-checking. Assim, definimos inicialmente quais seriam as características essenciais do artefato que iríamos propor.

Segundo Santos (2018), um artefato pode ser classificado em diferentes categorias conforme seus níveis de tangibilidade, que podem ir desde o conceito utilizado para operar uma solução até o produto em operação no ambiente de onde se originou a demanda. Entre os tipos mais aceitos de artefatos estão constructos, modelos, métodos e instanciações. O principal artefato que estamos propondo é um modelo, ou seja, a descrição de um sistema que combina constructos (ou conceitos) previamente 
definidos. Ainda assim, a fim de testar a aplicabilidade do modelo, também foi necessário estabelecer um método de checagem e uma instanciação, materializada no mínimo produto viável que escolhemos chamar de plataforma Sem Migué.

Para definir as características essenciais do modelo e subsidiar a criação de um método de checagem próprio, analisamos as metodologias de duas agências de factchecking nacionais: Lupa e Aos Fatos. Essas são as duas únicas organizações jornalísticas signatárias da International Fact-Checking Network (IFCN) em operação no Brasil atualmente. O código de princípios da IFCN possui cinco pontos que são exigidos de seus membros: a) Apartidarismo e equidade na checagem; b) Transparência das fontes utilizadas na verificação; c) Transparência das fontes de financiamento do projeto; d) Transparência da metodologia de checagem; e) Compromisso com uma política de correções do trabalho publicado.

Além dessas diretrizes, cada uma das agências selecionadas segue seus próprios procedimentos de apuração, que buscamos identificar por meio de visita às seções de apresentação nos respectivos sites. Ambas adotam procedimentos similares de seleção de pauta: as informações são escolhidas conforme a sua relevância para o interesse público, o perfil de quem as proferiu e o tamanho da repercussão do conteúdo nas mídias. Tanto a Lupa quanto Aos Fatos excluem do escopo de checagem opiniões e previsões de futuro. A Lupa acrescenta que também não checa conceitos amplos especificando os tipos de informação que apura: documentos históricos, dados estatísticos e comparações ou afirmações sobre a legalidade ou constitucionalidade de um fato.

Os dois veículos adotam etiquetas para classificar o grau de veracidade das informações. As da Lupa são "falso", "contraditório", "exagerado", "subestimado", "insustentável", "verdadeiro, mas", "verdadeiro", "ainda é cedo para dizer" e "de olho". Já as etiquetas de Aos Fatos são: "falso", "contraditório", "exagerado", "insustentável", "distorcido", "impreciso" e "verdadeiro". O uso dessas categorias sugere uma tentativa de abarcar a complexidade informativa das declarações e boatos, reconhecendo e apontando onde há factualidade nas informações supostamente mentirosas e onde há incorreções nas frases supostamente verdadeiras.

Uma das particularidades da metodologia informada pela Lupa é o foco quase exclusivo no uso de fontes oficiais - mesmo quando não há bases de dados acessíveis, os repórteres são orientados a recorrer à Lei de Acesso à Informação (LAI) e assessorias de imprensa. Como formas complementares de apuração, pode-se pedir a análise de especialistas e ir a campo com equipamentos fotográficos, de áudio e/ou vídeo. Quando 
se trata da apuração de falas de políticos e autoridades públicas, a agência também solicita a posição oficial de quem foi checado.

Já a metodologia descrita por Aos Fatos utiliza a expressão "fontes de origem confiável" para orientar os checadores em suas apurações. As fontes oficiais são consultadas conforme a necessidade e, se não forem consideradas suficientes, os repórteres devem recorrer a fontes alternativas.

Nosso projeto se apropriou de elementos dessas duas metodologias para elaborar um conjunto de diretrizes que pudesse orientar os participantes do primeiro experimento com nosso modelo de checagem de fatos. Como as agências organizam o trabalho em torno de uma estrutura empresarial - com equipe de profissionais com vínculo empregatício e pagamento de salários -, seria necessário implementar adaptações, visto que nossa proposta se inspira em comunidades abertas com dinâmica distribuída. Chris Anderson (2012) defende esse tipo de organização em oposição aos modelos de negócio tradicionais:

A Web permite que as pessoas demonstrem o que podem fazer,
independentemente da escolaridade e dos antecedentes. Também
possibilita a formação de grupos de indivíduos, que passam a trabalhar
juntos, com facilidade, fora do contexto de uma empresa, não importa
que como "trabalho" ou como "diversão". E essas organizações mais
informais estão muito menos sujeitas às restrições de geografia.
(ANDERSON, 2012, p. 175)

Nesse contexto, a prática jornalística se expandiu, podendo ser encontrada tanto no âmbito de estruturas organizacionais mais tradicionais como em dinâmicas emergentes menos institucionalizadas. Na era dos meios de comunicação de massas, os jornais, o rádio e a televisão operavam na lógica econômica da escassez de recursos, então o produto jornalístico foi viabilizado em modelos industriais centralizados nas mãos dos proprietários de veículos de imprensa. Com a reconfiguração do ecossistema de mídia, emergiu o paradigma da abundância e o jornalismo pós-industrial, que multiplicou o número de atores e organizações envolvidos na produção noticiosa e afetou as formas tradicionais de financiamento (CAPOANO, 2018).

Ainda que a inserção de uma multiplicidade maior de atores nas dinâmicas de produção e difusão de conteúdo informativo possa parecer, à primeira vista, a realização de uma utópica democratização da mídia, esse fenômeno também trouxe à tona uma série de problemas. Na prática, o que se observa de uma forma bastante evidente é que a lógica da abundância tem sido utilizada para fomentar um ambiente polarizado, muito mais reativo que reflexivo, onde surgem novos modos de produção, compartilhamento 
e consumo de notícias muito pouco apegados a regulações ou padrões editoriais (SANTAELLA, 2018).

Trata-se, portanto, de um terreno fértil para a proliferação de campanhas de desinformação, que empregam técnicas cada vez mais sofisticadas de disseminação de mentiras. Contudo, não há no horizonte nenhum sinal de retorno ao paradigma da exclusividade do fluxo de informações de um para muitos - e nem é esse o objeto da nossa defesa. A lógica da abundância e a descentralização devem permanecer como características fundamentais das redes. Por isso defendemos o desenvolvimento de soluções que auxiliem os usuários dessas redes digitais a lidar com agentes de desinformação, sem a pretensão de eliminar definitivamente o problema. É nesse sentido que o modelo colaborativo e descentralizado de checagem foi idealizado.

A fim de sistematizar esse artefato e elaborar um plano de ação, utilizamos como base o Canvas para modelos de negócio proposto por Alexander Osterwalder e Yves Pigneur (2011), que tem servido para compreender e redesenhar não apenas iniciativas do mundo empresarial e corporativo, mas também organizações sem fins lucrativos e mesmo projetos cívicos, como é o caso deste trabalho. Após algumas adaptações estratégicas, chegamos ao quadro a seguir. Na sequência, resumimos as escolhas para cada um dos nove tópicos que compõem esse plano de ação.

Figura 1: Modelo Canvas do projeto Sem Migué

\begin{tabular}{|c|c|c|c|c|c|}
\hline \multirow{2}{*}{ 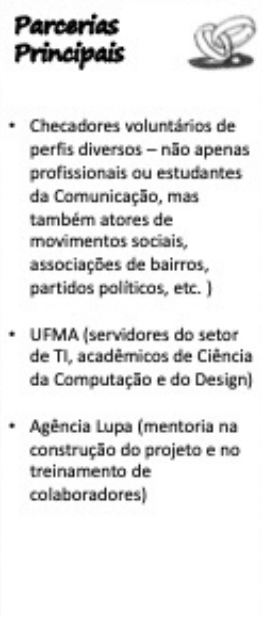 } & $\begin{array}{l}\text { Attividades-Chave } \\
\text { - Recrutar e treinar } \\
\text { colaboradores para aplicação } \\
\text { da metodologia de fact- } \\
\text { checking. } \\
\text { - Moderar/organizar a } \\
\text { disponibilizaşa de fatos } \\
\text { verifićsveis. } \\
\text { - Apuração e checagem dos } \\
\text { fatos. } \\
\text { - Distribuição dos conteúdos } \\
\text { em outras midias. }\end{array}$ & \multirow{2}{*}{\multicolumn{2}{|c|}{ 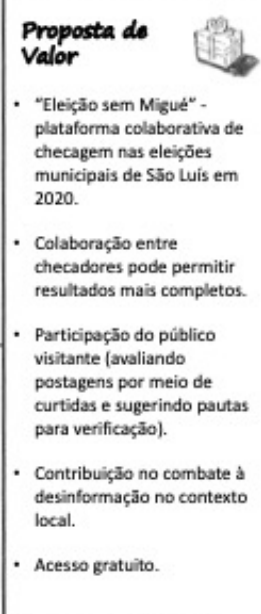 }} & $\begin{array}{l}\text { Ralacionamento } \\
\text { com os páblicos } \\
\text { - Checadores: estímulo à } \\
\text { cocriaçăo e fortalecimento } \\
\text { da comunidade por meio de } \\
\text { um grupo de colaboradores } \\
\text { no Whatsopp; } \\
\text { - cidadāos visitantes: self- } \\
\text { service (qualquer pessos } \\
\text { pode acessar a plataforma, } \\
\text { curtir posts e sugerir pautas). }\end{array}$ & \multirow{2}{*}{$\begin{array}{l}\text { Pablicos } \\
\text { Implactados } \\
\text { - Checadores voluntários; } \\
\text { - Cidadisos ludovicenses } \\
\text { - Candidatos a prefeito; } \\
\text { - Candidatos a vereador. }\end{array}$} \\
\hline & $\begin{array}{l}\text { Riscos a enfrantar } \\
\text { - Informaçōes indisponiveis } \\
\text { nos portais de } \\
\text { transparência ou SIC; } \\
\text { - Baixa adeșo de } \\
\text { collaboradores. } \\
\text { - Indisponibilidade dos } \\
\text { parceiros da UFMA }\end{array}$ & & & $\begin{array}{l}\text { Canals } \\
\text { - Site próprio; } \\
\text { - Plataformas de redes } \\
\text { sociais (Instogram, } \\
\text { Twitter, Facebook); } \\
\text { - Whatsapp Business para } \\
\text { público em geral; } \\
\text { - Grupo de Whatsapp para } \\
\text { colaboradores. }\end{array}$ & \\
\hline \multicolumn{3}{|c|}{$\begin{array}{l}\text { Estrutuma de } \\
\text { Custo } \\
\text { - Desenvolvimento e hospedagem do site; } \\
\text { : Crisçăo de marca e identidade visual; } \\
\text { - Impulsionamento nas redes sociass }\end{array}$} & \multicolumn{3}{|c|}{$\begin{array}{l}\text { Modelo } \\
\text { de Sustentabilidade } \\
\text { - Parceria com técnicos de Tl e estudantes de Design da UFMA } \\
\text { : Parceria com Agéncia Lupa } \\
\text { - Crowdfunding; } \\
\text { - Googie Adsense. }\end{array}$} \\
\hline
\end{tabular}

Fonte: Elaborado pelos autores. 
No modelo original, este primeiro componente é denominado "segmentos de clientes". A fim de adaptar esse elemento à lógica do nosso projeto, adotamos a nomenclatura "públicos impactados". A modificação ocorreu porque percebemos que as relações de consumo não seriam predominantes e que outros tipos de vínculo seriam formados entre os atores envolvidos no processo. Assim, chegamos aos segmentos do público que pretendíamos impactar: checadores voluntários, eleitores ludovicenses de um modo geral, candidatos ao cargo de prefeito e candidatos ao cargo de vereador. Essa separação foi realizada a partir dos diferentes tipos de vínculo que poderiam ser criados e que explicaremos melhor nos itens a seguir.

\section{Proposta de Valor}

Componente central do Canvas, a proposta de valor consiste não apenas nos serviços ou produtos ofertados, mas também em tudo aquilo que os qualifica e diferencia. Entre esses elementos, o fator inovação é um dos que mais costumam ser lembrados ao elaborar estratégias para solucionar problemas e conquistar a adesão do público. No caso da plataforma Sem Migué, a novidade está na adoção de uma dinâmica de fact-checking caracterizada pela dinâmica distribuída.

Ao abrir a posição de checador para qualquer pessoa que queira contribuir com o processo, buscamos enfrentar o problema da desinformação a partir de uma lógica de abundância e não de escassez. Em outras palavras, buscamos inspiração mais em economias baseadas na cultura da dádiva - construídas a partir do valor de uso e compartilhamento de bens e serviços - do que no paradigma dominante na economia de mercado capitalista, que se adapta ao valor de troca em meio à escassez de recursos (JEMIELNIAK; PRZEGALINSKA, 2020).

Apesar de as economias da dádiva já existirem há muito tempo, com suas características podendo ser atribuídas até mesmo a sociedades pré-históricas, compreendemos que a lógica da abundância também está presente no paradigma emergente dos modelos de negócios que têm sido frequentemente colocados dentro de categorias como sociedade colaborativa, economia do compartilhamento, gig economy, economia da confiança, etc. (JEMIELNIAK; PRZEGALINSKA, 2020; FRENKEN; SCHOR, 2017; RAVANELLE, 2019; COSTA, 2018).

A informação é um dos bens que melhor ilustram a lógica da abundância. Tratase de um recurso produzido, compartilhado e consumido em proporções sem precedentes. Considerando que é nesse contexto que emerge o fenômeno da desinformação, também buscamos nos distanciar da lógica da escassez ao pensar nossa 
plataforma. Não cobramos nada em troca do serviço de checagem. A ideia foi disseminar a prática do fact-checking como algo que todos podem fazer, uma vez que apenas as iniciativas de jornalismo profissional isoladas não têm nem a capacidade de rastrear e checar a totalidade das peças de desinformação que surgem nas redes, nem a garantia de que suas reportagens alcançam todas as pessoas afetadas pelo conteúdo enganoso.

Por isso, a proposta de valor inclui o recrutamento e treinamento de colaboradores voluntários que podem ou não ser jornalistas profissionais. Na plataforma Sem Migué, um mesmo fato pode contar com uma multiplicidade de checagens postadas por autores diversos, cabendo ao público avaliar os resultados. Nesse sentido, buscamos promover um trabalho de educação para as mídias não apenas entre os colaboradores do projeto, mas também com o público visitante da plataforma. Nossa intenção foi estimular os visitantes a refazer o percurso de cada checagem por meio dos links disponibilizados pelos voluntários. Conforme consta no Canvas, também pretendíamos fomentar a participação externa com a função de curtidas, mas essa funcionalidade acabou ficando de fora do mínimo produto viável.

\section{Canais}

Os canais são os meios de comunicação que utilizamos para levar a proposta de valor até os públicos que desejávamos impactar. Nesse sentido, o canal central foi o próprio site da plataforma, onde publicamos os fóruns de checagem, descrevemos nossa metodologia e disponibilizamos um formulário para envio de sugestões de pauta. O site foi hospedado no portal da Universidade Federal do Maranhão (UFMA), graças a uma parceria com a Superintendência de Tecnologia de Informação.

Também foram utilizados perfis no Instagram, Twittere Facebook - já que esses sites assumem um papel importante na difusão de informações de maneira rápida e facilmente escalável. Também disponibilizamos ao público um número de Whatsapp Businness, com o propósito de receber sugestões de pauta e enviar aos contatos cadastrados links dos fóruns de checagem na plataforma.

Reunimos os voluntários em um grupo privado no Whatsapp com o objetivo de notificar a publicação de novos fóruns, facilitar a troca de informações e fortalecer a rede de colaboração. Além disso, também trocamos mensagens por e-mail e realizamos a reunião de treinamento por meio da plataforma Google Meet, visto que o experimento ocorreu em meio à pandemia de Covid-19, quando o recurso das videoconferências foi amplamente empregado como forma de respeitar o distanciamento social recomendado pelas autoridades sanitárias. 


\section{Relacionamento com os públicos}

Este componente do quadro também foi adaptado, substituindo o termo "relacionamento com os clientes" por "relacionamento com os públicos". Idealizamos dois tipos de vínculo: a cocriação e o self-service. O primeiro caracteriza o relacionamento com a equipe de colaboradores do projeto, de modo a estimular a participação voluntária. Já o segundo foi pensado para que os visitantes navegassem pela plataforma de forma autônoma. Esse vínculo de "autoatendimento" não deveria nos impedir de estabelecer com alguns deles um contato mais direto, uma vez que na divulgação do experimento anunciamos canais para envio de críticas e sugestões de melhoria da plataforma.

\section{Modelo de Sustentabilidade}

No quadro original, este item era intitulado "Fontes de Receita", referindo-se ao valor que os clientes de uma empresa estão dispostos a pagar para receber um determinado serviço ou produto. Como o projeto tem o objetivo de disseminar o factchecking ao maior número possível de pessoas, foi preciso encontrar maneiras de sustentar a operação da plataforma sem deixar de lado a gratuidade do serviço ofertado aos visitantes. Como não dispúnhamos de fontes de receita, buscamos cobrir os custos operacionais prioritariamente por meio de parcerias estratégicas.

O apoio da UFMA foi concretizado por meio da Superintendência de Tecnologia da Informação (STI), cuja equipe colaborou na criação de uma plataforma dentro do site do Laboratório de Pesquisas e Práticas Jornalísticas (LABJOR). Também conseguimos parceria com o Laboratório de Design Social (LABDES) da universidade, que desenvolveu a marca e a identidade visual da plataforma Sem Migué.

O nosso Canvas previa uma parceria com a Agência Lupa para o treinamento dos voluntários, mas não foi possível concretizar esse apoio. Por isso, desenvolvemos nossa própria oficina de checagem. Também não conseguimos viabilizar a parceria prevista com pesquisadores da área de TI. As campanhas de crowdfunding e a ativação do serviço Google Adsense que constam no nosso quadro também não foram executadas, uma vez que as parcerias firmadas foram suficientes para viabilizar um produto mínimo viável.

\section{Riscos a enfrentar}

Este componente substitui a seção original "Principais Recursos", porque julgamos que o exercício de descrição dos recursos humanos, físicos e intelectuais já 
estava suficientemente contemplado em outras partes do nosso Canvas. Assim, preferimos utilizar esta seção para fazer um mapeamento de riscos que podem ameaçar o sucesso do experimento. Identificamos como principais: a indisponibilidade de fontes de checagem, a baixa adesão de colaboradores nos fóruns e a dificuldade de firmar as parcerias previstas no modelo de sustentabilidade. As estratégias previstas para mitigação desses riscos incluíram consulta prévia aos bancos de dados disponíveis online e formas alternativas de angariar recursos para cobrir os custos operacionais que, como vimos, não foram necessárias.

\section{Atividades-Chave}

As atividades mais importantes do Sem Migué representam também as quatro etapas fundamentais do trabalho: recrutamento e treinamento de checadores, seleção e organização dos fóruns de checagem, realização do trabalho de fact-checking propriamente dito e distribuição dos resultados por meio das redes sociais on-line. As duas primeiras ficam a cargo do moderador da plataforma e as duas últimas são compartilhadas por todos os participantes.

\section{Parcerias Principais}

No Sem Migué, os parceiros representam um componente essencial, uma vez que os voluntários do projeto são indispensáveis para a materialização do modelo de checagem colaborativa. Nesse sentido, foi estratégica a abertura do recrutamento para atores de diversos campos sociais - não apenas do Jornalismo e da Comunicação. Nossa intenção era viabilizar espaços abertos para a criação de vínculos entre esses colaboradores. Desde o nosso planejamento, concebemos o modelo de checagem da plataforma Sem Migué como um processo comunicacional em que poderiam se cruzar - ou até mesmo se chocar - interesses e motivações distintas para utilizar a plataforma e colaborar com o trabalho de verificação. Mas todos estariam inseridos numa comunidade com o propósito de lidar com o problema da desinformação. Outras parcerias previstas eram as já citadas anteriormente - tendo sido concretizado apenas o apoio da STI e do LABDES da UFMA.

\section{Estrutura de Custo}

Inicialmente, previmos custos com desenvolvimento e hospedagem do site da plataforma, criação de marca e identidade visual, e a possibilidade de impulsionamento de conteúdo nas redes sociais on-line. Dessas, a última foi a única que não 
concretizamos. Conforme especificamos no nosso modelo de sustentabilidade, os dois primeiros itens foram possibilitados por meio das parcerias.

\section{Definindo as diretrizes de checagem}

Os nove itens apresentados acima ilustram o modelo que planejamos testar por meio da definição de um método de checagem e da instanciação de uma plataforma de fact-checking. Como dissemos anteriormente, o método adotado foi uma adaptação das diretrizes das agências Lupa e Aos Fatos. Evidentemente, as especificidades dizem respeito aos propósitos de colaboração e descentralização do nosso projeto. Sistematizamos os nossos procedimentos de checagem em seis tópicos: 1) seleção, 2) fóruns de verificação, 3) fontes de checagem, 4) etiquetas, 5) autonomia dos colaboradores e 6) moderação dos comentários.

Assim como nos veículos de checagem nacionais, priorizamos na seleção de pautas as informações proferidas nas falas de políticos e autoridades públicas, mas também previmos a possibilidade de checar boatos que circulassem nas redes sociais on-line. Não checamos opiniões ou previsões. Como o experimento seria realizado durante período da campanha eleitoral, buscamos apenas assuntos relevantes para as eleições municipais de São Luís e excluímos dessa seleção promessas de candidatos. As informações cadastradas nos fóruns teriam que ser verificáveis em documentos e bancos de dados públicos e confiáveis.

Quanto aos fóruns de verificação, a metodologia do Sem Migué preconiza que cada fórum corresponde a uma única unidade informativa - por exemplo, uma única frase do discurso de um candidato ou, no caso de um boato, somente o aspecto-chave que é posto em dúvida. Esse requisito tem o objetivo de fazer com que todos os participantes de um mesmo fórum apurem e avaliem o mesmo dado, permitindo ao público leitor comparar e avaliar como diferentes atores podem checar uma mesma informação.

Já a escolha das fontes de checagem precisa ser guiada pela transparência. Os colaboradores foram orientados a incluir sempre os links do material utilizado - caso não estivessem disponíveis on-line, seria preciso compartilhar prints, fotos, áudios e outros tipos de registro, deixando claro como as informações foram obtidas. Foi terminantemente proibida a utilização de fontes anônimas. As fontes oficiais deveriam ser sempre consultadas, mas decidimos que fontes alternativas também seriam utilizadas caso as oficiais não fossem suficientes ou confiáveis. Os checadores foram orientados a 
utilizar fontes confiáveis e primárias - por exemplo, estudos científicos ou relatórios de organizações e pessoas com legitimidade para falar sobre um determinado assunto.

Definimos cinco etiquetas que deveriam ser atribuídas pelos colaboradores a cada informação no início das postagens nos fóruns. Os dados poderiam ser classificados como: verdadeiro, descontextualizado, exagerado, não dá para afirmar (quando não há dados disponíveis para comprovar a veracidade) ou falso. Os checadores tiveram autonomia para escolher suas etiquetas e publicar as suas próprias reportagens. Os posts tinham sempre a identificação dos autores, e a plataforma disponibilizava um perfil de todos os checadores - expondo vínculos institucionais de trabalho, de filiação partidária, de associação comunitária ou de qualquer outra natureza relevante para a transparência.

Por fim, as diretrizes de trabalho do projeto Sem Migué deixavam clara a política de moderação das postagens feitas pelos colaboradores voluntários nos fóruns. As checagens não foram submetidas à revisão ou aprovação prévia, mas o moderador teria a prerrogativa de excluir contribuições que divulgassem dados pessoais de terceiros ou manifestassem qualquer tipo de discurso de ódio em virtude de gênero, cor, etnia, credo e orientação sexual. Não houve necessidade de apagar nenhum post.

Definidos os artefatos do tipo modelo e método, partimos para a instanciação do mínimo produto viável. Nesse processo, ainda que não tenhamos implementado todas as funcionalidades previstas inicialmente, o serviço que conseguimos viabilizar foi suficiente para coletar os resultados que apresentamos no próximo tópico e que servirão para elaborar uma revisão do modelo Sem Migué.

\section{Potencialidades e limitações do modelo}

O teste do mvp ocorreu de 17 de setembro até 29 de novembro de 2020. A plataforma Sem Migué foi lançada juntamente com a campanha de recrutamento de voluntários nas redes sociais on-line. A marca foi desenvolvida com base na proposta regional do projeto, utilizando como referência o cazumbá, enigmático personagem da cultura popular do Maranhão. Na imagem, o nariz foi alongado em alusão a Pinóquio boneco de madeira da literatura infantil cujo nariz aumentava sempre que contava uma mentira. Ao nome do projeto, acrescentamos a assinatura "nas eleições" para deixar claro que se tratava de uma edição voltada para o período eleitoral.

Figura 2: Marca do projeto Sem Migué 


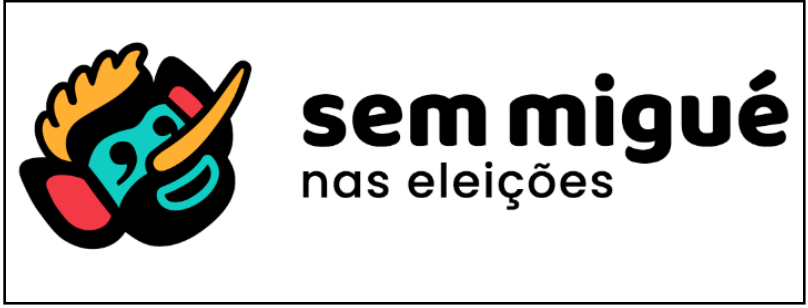

Fonte: $<$ https://www.instagram.com/semmigueslz/>

Avaliamos os resultados do experimento a partir da análise das métricas do conteúdo publicado na plataforma, de três questionários aplicados com os participantes voluntários e da observação participante realizada ao longo de todo o plano de ação. Durante as duas primeiras semanas, o plano consistiu em promover a plataforma nas redes sociais on-line e tentar pautar os veículos de imprensa locais. Esse período foi utilizado ainda para entrar em contato com as assessorias de comunicação de todos os candidatos a prefeito de São Luís, convidando-as a participar do projeto. Uma vez que a ideia era viabilizar uma comunidade de checagem aberta sem exigir apartidarismo dos voluntários, presumimos que haveria o interesse de ocupar esse espaço. Entretanto, apenas um assessor se inscreveu, mas acabou desistindo de participar.

Ainda assim, quando começamos a publicar os fóruns de checagem na plataforma, instauramos a rotina de notificar as equipes de campanha sempre que seus candidatos tinham falas checadas, abrindo espaço para que se explicassem. Na maioria das vezes, as assessorias não enviavam resposta alguma. Nos bastidores, alguns nos ignoravam, como foi o caso da equipe do prefeito eleito Eduardo Braide (Podemos), outros reclamavam das checagens negativas a seus assessorados. Houve um episódio de tentativa de intimidação por parte da equipe do candidato Duarte Júnior (Republicanos), segundo colocado no pleito. Depois de pedir uma resposta para o fórum que apurava se ele havia respondido a processo por agredir uma pessoa idosa, recebemos apenas a cópia de uma decisão judicial condenando um blogueiro local por ter publicado uma matéria sobre o assunto. Mantivemos a publicação, e o candidato acabou não levando o caso à Justiça.

O incômodo manifestado por alguns assessores e a postura aparentemente desinteressada de outros podem se dever em parte ao ineditismo da iniciativa no âmbito da cidade de São Luís. As eleições de 2020 foram as primeiras em que políticos locais tiveram de lidar com a checagem de seus discursos nos debates, entrevistas e propagandas eleitorais. Além do Sem Migué, também surgiu outra iniciativa de factchecking no mesmo período: o "Rumbora Marocar". De repente, as campanhas tiveram 
de lidar com dois projetos até então desconhecidos e com a proposta de questionar seus candidatos. A desconfiança não é uma reação estranha para quem se sente mais confortável lidando com um jornalismo predominantemente declaratório. Assim, o modelo tem um potencial a ser desenvolvido no sentido de tirar lideranças políticas de suas zonas de conforto.

Foram checadas de todos os candidatos - com exceção de Adriano Sarney (PV), que desistiu do pleito ainda no início da campanha. Ao longo do período de propaganda eleitoral, tentamos checar mais frases dos candidatos melhor posicionados nas pesquisas de intenção de voto. Assim, cadastramos 10 fóruns para apurar afirmações de Eduardo Braide (Podemos), 6 de Duarte Júnior (Republicanos), 4 de Neto Evangelista (Democratas), 4 de Rubens Pereira Júnior (PCdoB), 4 de Bira do Pindaré (PSB), 3 de Silvio Antônio (PRTB), 2 de Jeisael Marx (Rede), 3 de Yglésio Moyses (PROS), 4 de Franklin Douglas (PSOL) e 2 de Hertz Dias (PSTU). Checamos ainda uma fala do candidato Carlos Madeira (Solidariedade), antes de sua desistência da disputa eleitoral. O então prefeito Edivaldo Holanda Jr. (PDT) e o governador do Maranhão Flávio Dino (PCdoB) também tiveram falas verificadas em um fórum de checagem para cada.

Todos os fóruns de verificação na plataforma tinham a mesma estruturação, exemplificada na Figura 3 abaixo. No título, havia sempre uma pergunta direcionando o aspecto a ser checado. Em seguida, uma pequena introdução contextualizava a pauta, precedendo o destaque da frase que deveria ser apurada. O texto introdutório trazia ainda o link para o conteúdo original - geralmente vídeos de entrevistas e debates publicados no Youtube. Utilizamos como ilustração um print de onde a informação foi retirada e finalizamos essa seção inicial com um pequeno parágrafo explicativo do projeto. Logo em seguida, havia a área destinada às checagens em formato de fórum.

Figura 3: Estrutura dos fóruns de verificação
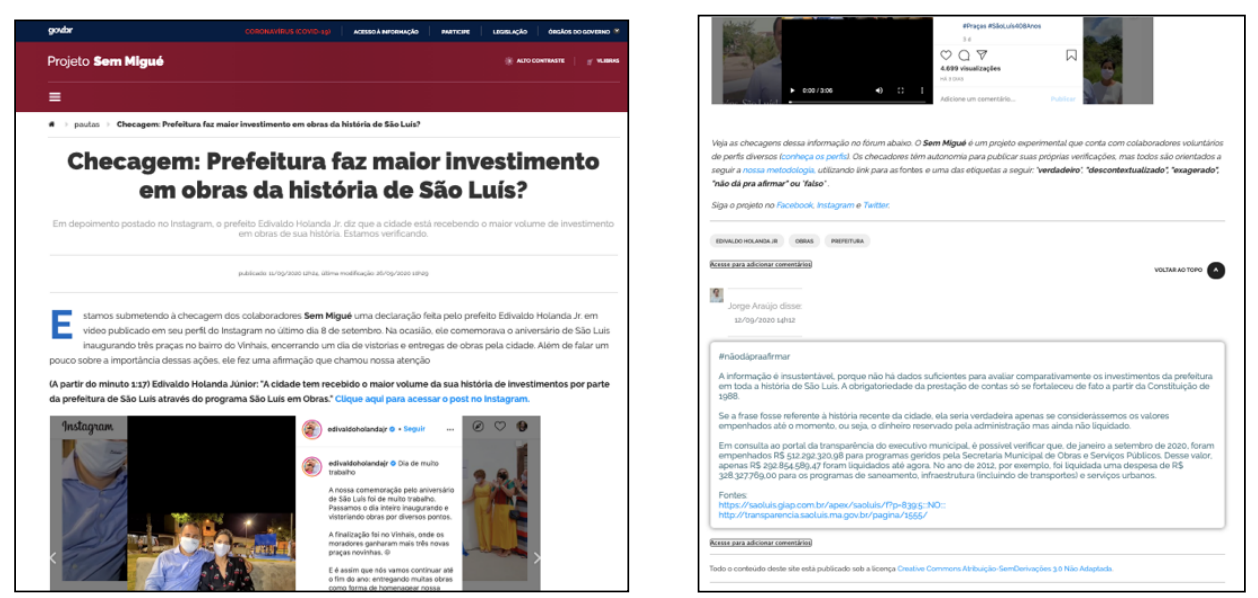
Fonte: < https://portalpadrao.ufma.br/labjor/sem-mique>

Até o dia 29 de novembro de 2020, foram publicados 46 fóruns de verificação e 63 checagens individuais. No processo de seleção de pautas, evitamos as informações cuja veracidade já havíamos confirmado previamente. Assim, obtivemos 27 etiquetas "falso", 17 etiquetas "descontextualizado", 9 etiquetas "exagerado", 7 etiquetas "não dá pra afirmar" e 3 etiquetas "verdadeiro". De acordo com dados obtidos pelo Google Analytics, a plataforma teve 6.502 visualizações no período entre 16 de outubro e 30 de novembro de 2020. A maior parte das visualizações de páginas do site do projeto tiveram origem em pesquisas no Google (36\%), em links diretos (22\%) - e somente depois vinham o Instagram (18\%), Twitter (16\%) e Facebook (6\%). Os picos de acesso ocorreram em 21 de outubro, um dia depois do debate realizado pelo jornal O Estado do Maranhão e Portal Imirante, e em 28 de novembro, véspera do segundo turno das eleições - as datas registraram, respectivamente, 370 e 343 visualizações.

Considerando que, segundo dados do Tribunal Superior Eleitoral, o município de São Luís tinha 669.954 eleitores aptos a votar nas eleições de 2020, o alcance da plataforma foi bastante reduzido. A isso devemos algumas possíveis razões: falta de recursos para impulsionamento de conteúdo, precariedade do engajamento conquistado entre as principais lideranças políticas, curto intervalo de tempo para consolidar uma rede de leitores assíduos, falta de influência da checagem de fatos na definição do voto. Apesar dessas limitações, conseguimos identificar um grande potencial pedagógico do modelo a partir da experiência com os participantes voluntários.

Um total de 36 pessoas se inscreveram no projeto, mas foram mantidos apenas os que participaram da oficina ou demonstraram interesse em assistir ao vídeo do treinamento. Assim, o experimento contou com 24 voluntários. Com os dados fornecidos no formulário de inscrição, obtivemos o perfil dos colaboradores. Quase todos declararam escolaridade de nível superior - 64\% disseram ter feito ou estar fazendo graduação e 33\% cursaram pós-graduação. As profissões mais apontadas no questionário foram estudante, professor e ocupações ligadas à área da Comunicação (jornalista, radialista, assessor de imprensa, social media e blogueiro). O grupo também contou com advogados, servidores públicos, empresário, produtora cultural, turismóloga e bibliotecária.

No ato da inscrição, os voluntários informaram ainda os motivos que os levaram a se interessar pelo projeto. As respostas a essa questão giraram em torno de interesses 
acadêmicos e cívicos. No geral, as explicações transmitiam uma inquietação com a crise das instituições democráticas e um desejo de contribuir para eleições mais transparentes e equilibradas. Saber essas motivações foi importante tanto para mapear expectativas como também para identificar os objetivos em comum que poderiam ser reforçados, facilitando a criação de vínculos entre os membros da comunidade que queríamos construir. As motivações declaradas dizem muito sobre o perfil do grupo, formado majoritariamente por pessoas inseridas no contexto acadêmico, com um certo nível de consciência política e, em alguns casos, de militância.

O segundo questionário preenchido pelos participantes do experimento teve o objetivo de avaliar a oficina de checagem realizada no dia 3 de outubro de 2020, por meio do Google Meet. A capacitação teve duração de quatro horas e o conteúdo foi dividido em duas partes. A primeira teve o objetivo de explicar o projeto Sem Migué, justificando nossa escolha por um modelo de checagem colaborativo e alinhando a metodologia adotada na plataforma. Na segunda parte, mostramos ferramentas e bases de dados úteis para o trabalho de apuração, intercalando essas dicas com exercícios práticos. Um total de 19 voluntários acompanharam o treinamento de forma síncrona. As respostas ao formulário de avaliação nos ajudaram a perceber que aspectos foram mais úteis e como poderíamos melhorar a oficina. Entre os aspectos positivos, os participantes enfatizaram sobretudo os exercícios práticos e as dicas de ferramentas e bases de dados que poderiam ser utilizadas na checagem. Já as críticas sugeriam melhorias na gestão do tempo. Recebemos algumas ponderações de que a oficina poderia ter sido mais curta ou dividida em mais de um dia para que a experiência fosse menos cansativa.

Já o terceiro questionário foi enviado aos voluntários quando encerramos o experimento. Dos 24 participantes, apenas 11 fizeram pelo menos uma publicação na plataforma. Ainda assim, solicitamos que todos preenchessem o formulário final inclusive aqueles que não participaram ativamente do processo. Uma das questões buscava mapear os principais motivos para eles não terem postado suas checagens. Praticamente todos os respondentes mencionaram falta de tempo. O segundo empecilho mais citado foi a insegurança ou falta de conhecimento. Duas pessoas relataram problemas pessoais e de saúde relacionados à Covid-19.

Ainda que mais da metade dos participantes não tenha publicado suas próprias reportagens e que a grande maioria dos fóruns não tenha tido mais do que uma única contribuição, consideramos que houve trabalho colaborativo. No questionário, fizemos essa pergunta aos checadores mais atuantes e apenas uma pessoa alegou ter feito $o$ 
trabalho de apuração sozinha. Todas as outras afirmaram ter recebido contribuições do moderador e/ou de outros colegas da comunidade de checagem. Por isso, embora os dados da tabela abaixo mostrem que os fóruns não tiveram muita diversidade de checagens postadas, concluímos que a colaboração se deu nos bastidores da plataforma.

Tabela 1: Número de checagens por fórum

\begin{tabular}{|c|c|c|c|c|}
\cline { 2 - 5 } \multicolumn{1}{l|}{} & Nenhuma checagem & Uma checagem & Duas checagens & Três checagens \\
\hline Número de fóruns & 1 & 31 & 10 & 4 \\
\hline
\end{tabular}

Fonte: Elaborado pelos autores

Até mesmo nos fóruns que obtiveram maior número de checagens, percebemos que houve pouca diversidade quanto ao uso das etiquetas. Em praticamente todos os casos, as apurações não divergiam muito entre si. Quando conversamos individualmente com alguns dos checadores mais ativos nos fóruns, descobrimos que eles tinham menos vontade de postar contribuições quando já havia uma checagem no fórum. Segundo eles, isso ocorria porque não dispunham de dados novos para enriquecer a discussão ou, às vezes, porque tinham receio de se indispor com os colegas que já haviam feito a apuração.

O questionário final listava ainda uma série de afirmações e pedia que os voluntários marcassem se concordavam ou discordavam totalmente ou parcialmente. Destacamos a seguir alguns resultados interessantes dessa seção. Em geral, o grupo tendeu a concordar totalmente que a experiência mudou a percepção de cada um sobre a cobertura jornalística das eleições, que foram adquiridas novas competências e habilidades e que a seleção de pautas de checagem foi condizente com a metodologia proposta. Por outro lado, em média, os voluntários concordaram apenas parcialmente que a experiência tenha mudado sua percepção sobre o discurso dos políticos, que a carga de treinamento tenha sido suficiente, que a metodologia proposta tenha dado conta de suprir as demandas de checagem e que o trabalho do Sem Migué tenha tido influência na decisão do seu próprio voto ou do voto de outras pessoas.

Outros resultados da experiência só puderam ser coletados a partir da observação participante, que - por conta do contexto pandêmico - adaptamos aos ambientes digitais onde ocorreu toda a comunicação entre participantes do estudo. A partir de conversas por chamada de vídeo ou mensagens de texto, identificamos que alguns voluntários se sentiam inseguros para fazer suas checagens porque percebiam 
que outros colegas da comunidade tinham mais experiência ou conhecimento das bases de dados necessárias para a apuração. Essa percepção reforçou a necessidade de ampliar as ações pedagógicas com o objetivo de dar mais autonomia e segurança aos colaboradores.

Além disso, ficou evidente que a principal dificuldade enfrentada pelos checadores que tentavam apurar informações junto às fontes oficiais foi a falta de dados disponíveis nos sites da Prefeitura, da Câmara Municipal e da Assembleia Legislativa. Quando não havia informações confiáveis on-line, recorríamos às assessorias de imprensa desses órgãos, mas, em diversas ocasiões, o trabalho era prejudicado pela demora no envio de uma resposta ou mesmo pela recusa de nos atender. Em um dado momento, uma funcionária responsável pelo atendimento à imprensa no poder executivo municipal alegou que o órgão não se envolveria nas eleições para justificar o fato de não atender nossos pedidos de informação. Portanto, confirmamos que a falta de transparência do poder público local é um aspecto bastante limitador para a prática do fact-checking.

Outro destaque pertinente à análise do experimento é a ausência de boatos na amostragem de informações selecionadas para os fóruns de checagem. Isso significa que todas as reportagens verificaram apenas a factualidade de dados proferidos pelos atores envolvidos no processo eleitoral, e que não houve prática de debunking - tipo de checagem muito mais sintomático daquilo que o fenômeno da desinformação traz de novidade. Duas informações que poderiam ter sido confirmadas como boatos acabaram sendo verificadas com etiquetas apontando que elas não eram de todo inverídicas. Elas foram pautadas nos fóruns "Duarte Jr respondeu a processo por agredir pessoa idosa?" e "Eduardo Braide não é investigado pelo Ministério Público Federal?". Ironicamente, ambos os candidatos envolvidos classificaram essas e outras acusações como "fake news" em debates e propagandas eleitorais. Isso nos leva a reforçar a ideia de que o termo tem sido indevidamente apropriado por políticos como uma arma retórica sempre que a divulgação de um dado ou notícia os desagrada.

\section{Considerações finais}

As impressões e os dados obtidos a partir da primeira experiência de aplicação do nosso modelo colaborativo e descentralizado de checagem de fatos evidenciam que há grandes desafios no que diz respeito à mobilização popular no combate à desinformação, bem como na construção de uma cultura de transparência sobretudo nos órgãos do poder público local. Entretanto, as dificuldades identificadas não 
diminuem a importância nem a necessidade de iniciativas que ajudem a democratizar o debate público e ampliar as possibilidades de controle social sobre órgãos e agentes públicos. Assim, é válida a utilização dos resultados da pesquisa para a atualização do modelo e testagem de novas versões dos seus artefatos derivados.

Para futuras aplicações, avaliamos como fundamental dedicar mais atenção ao caráter pedagógico desse trabalho. Isso ficou bastante claro nas avaliações de vários dos participantes da plataforma Sem Migué. Mesmo aqueles que não contribuíram ativamente nos fóruns de checagem puderam perceber como a prática do fact-checking requer tempo, conhecimento e recursos para ser executada - por isso, talvez passem a valorizar mais o trabalho jornalístico, seja ele realizado em contextos mais ou menos institucionalizados. Além disso, eles relataram uma mudança na forma de enxergar a cobertura noticiosa das eleições, o que pode sugerir uma recepção mais crítica dos conteúdos que recebem.

Outra possível alteração diz respeito à implementação de mais autonomia aos checadores na definição de etiquetas e na seleção de pautas. Neste primeiro experimento, a escolha das informações a serem checadas ficou centralizada na figura do moderador, mas consideramos que seria interessante experimentar uma dinâmica distribuída desde o início do processo. Essa mudança aproximaria mais ainda a proposta de checagem colaborativa dos modelos de comunidades abertas - nos quais os riscos são geralmente compensados pelo ganho em aprendizagem e potencial para inovação.

\section{Referências}

ANDERSON, Chris. Makers: a nova revolução industrial. Tradução: Afonso Celso da Cunha Serra. Rio de Janeiro: Elsevier, 2012.

BENKLER, Yochai; FARIS, Robert; ROBERTS, Hal. Network Propaganda: manipulation, disinformation and radicalization in American politics. Oxford: Oxford University Press, 2018.

CAPOANO, Edson et al. Como se banca o jornalismo: Modelos, tendências e reflexões sobre financiamento de mídia. São Paulo:[sn], 2018.

COSTA, Ramon Bezerra. Economia da confiança: comunicação, tecnologia e vinculação social. Curitiba: Appris, 2018.

FRENKEN, Koen; SCHOR, Juliet. Putting the sharing economy into perspective. Environmental Innovation and Societal Transitions, volume 23, pp. 3-10, 2017.

GIL, Antônio Carlos. Como elaborar projetos de pesquisa. 4ed. São Paulo: Atlas, 2008.

HAIDEN, Leonie; ALTHUIS, Jente. The Definitional Challenges of Fake News. In: International Conference on Social Computing, Behavior-Cultural Modeling, and Prediction and Behavior Representation in Modeling and Simulation, Washington, 2018.

JEMIELNIAK, Dariusz; PRZEGALINSKA, Aleksandra. Collaborative Society. Cambridge, MA: The MIT Press, 2020.

MANTZARLIS, Alexios. Fact-checking 101. In: Journalism, 'Fake News' \& Disinformation: Handbook for Journalism Education and Training. Paris: UNESCO, 2018. 
MENDONÇA, Ricardo Fabrino; FREITAS, Viviane Gonçalves. Fake News e o repertório contemporâneo de ação política. In: Encontro da COMPOLÍTICA, v.8, Brasília, 2019.

MOOGK, Dobrila Rancic. Minimum viable product and the importance of experimentation in technology startups. Technology Innovation Management Review, v. 2, n. 3, 2012.

NORRIS, Pippa; INGLEHART, Ronald. Cultural backlash: Trump, Brexit, and authoritarian populism. Cambridge University Press, 2019.

OSTERWALDER, Alexander; PIGNEUR, Yves. Business model generation: inovação em modelos de negócios. Alta Books Editora, 2011.

RAVENELLE, Alexandrea J. Hustle and Gig: struggling and surviving in the sharing economy. Oakland, California: University of California Press, 2019.

REIS, Julio C.S.; MELO, Philipe; GARIMELLA, Kiran; BENEVENUTO, Fabrício. Can WhatsApp benefit from debunked fact-checked stories to reduce misinformation? Harvard Kennedy School Misinformation Review, 2020.

SANTAELLA, Lúcia. A Pós verdade é verdadeira ou falsa? Barueri: Estação das Letras e Cores, 2018.

WARDLE, Claire; DERAKHSHAN, Hossein. Information disorder: Toward an interdisciplinary framework for research and policy making. Council of Europe report, v. 27, 2017.

\begin{abstract}
:
The aim of this research is to test the applicability of a collaborative and decentralized model of fact-checking during the 2020 elections in São Luís/MA. The model was materialized into a platform called "Sem Migué", in which volunteers had the opportunity to publish their own fact checks in the form of verification forums. The experiment seeks to investigate how this practice could help the participants deal with disinformation. The results will be used as resources in the development of an updated version of the model.
\end{abstract}

KEYWORDS: Disinformation; Democracy;

Journalism; Fact-checking. 


\section{RESUMEN:}

El objetivo de esta investigación es poner a prueba la aplicabilidad de un modelo colaborativo y descentralizado de verificación de hechos (fact-checking) en el transcurso de las elecciones municipales del 2020 en São Luís, Brasil. Este modelo se materializó a través de una plataforma llamada "Sem Migué", en la que voluntarios tuvieron la oportunidad de publicar sus verificaciones de hechos en foros virtuales. El experimento pretende investigar como esta práctica puede apoyar a los usuarios a hacer frente al fenómeno de la desinformación. Los resultados subsidiarán el desarrollo de una versión actualizada del modelo.

PALABRAS-CLAVES:

Desinformación;

Democracia; Periodismo; Fact-checking. 